\title{
The feasibility and economic efficiency of selective modernization solutions in a single- family house located in Siemianice near Słupsk
}

\author{
Agata Stolarska ${ }^{1, *}$, Jarosław Strzałkowski ${ }^{1}$, Michał Szczeciński ${ }^{1}$ \\ ${ }^{1}$ Department of Building Physics and Building Materials, Faculty of Civil Engineering and Architecture, \\ West Pomeranian University of Technology Szczecin, al. Piastów 50, 70-311 Szczecin, Poland
}

\begin{abstract}
This study presents the results of the analysis on the energy balance of a single-family residential home built in 1986. The authors assess the proposed construction improvements in terms of their ability to enhance the building's energy efficiency and comfort. The studies were carried out for the needs of the owners who saw the necessity of reducing the maintenance and heating costs of the house and of improving their living conditions. The on-site studies and analyses of the building concerning the calculations for the proposed variants of solutions have pointed to the necessity and relevance of a thermal modernization of the building. The analyses took into consideration the growing requirements of thermal insulation of walls, the $E P$ factor and the growing use of energy from renewable sources. The proposed modernization steps and energy audit calculations helped to select the most efficient solution.
\end{abstract}

\section{Introduction}

Energy efficiency and $\mathrm{CO}_{2}$ emission reduction are among the main objectives of the EU Member States. The introduction of the directives [1,2] requires the implementation of thermal modernizations in existing buildings. A large energy saving potential can be seen in older buildings, for example those constructed in the 1970s [3]. For best results, however, it is necessary to optimize the procedures related to the renovation of buildings. Among others, studies are carried out on the economic efficiency and relevance of replacing window woodwork and internal installations and insulating walls [4-7]. Comparisons are also made of energy efficiency calculations with the measurement data obtained from onsite studies [8]. The article [9], among others, presents the results of measurements of parameters required for the determination of energy consumption in a typical single-family building. The obtained thermal diagnostic results were useful in the analysis of the building's energy consumption at four successive stages of modernization. The measures included the improvement of insulation of walls and windows, installation of mechanical ventilation with heat recovery, improvement of airtightness and replacement of the boiler. Before the modernization, the primary non-renewable energy ratio was $243 \mathrm{kWh} /\left(\mathrm{m}^{2}\right.$ year), while after the renovation it decreased to $147 \mathrm{kWh} /\left(\mathrm{m}^{2}\right.$ year $)$. However, the building still

*Corresponding author: siwinska@zut.edu.p1 
could not meet the requirements for newly constructed single family homes in Poland. Nevertheless, it has been shown that the thermal diagnostic performed both before and after the thermal modernization enables carrying out an effective modernization process and achieve greater energy savings.

In turn, the paper [10] presented data on heating energy consumption taken from audits of 193 European residential buildings in five countries. Unfortunately, the average heating energy consumption for Polish buildings was listed as having the highest values.

Among the reasons that lead the authors of this article to take up the topic of thermal modernization of the studied building was a desire to reduce the maintenance and heating costs and to improve its living comfort. An interview conducted with the inhabitants revealed that for a number of years they gradually improved its technical condition which unfortunately involved continuous repairs and high costs. Therefore, the aim of the present paper is to carry out an energy balance and to offer the best energy efficiency solutions. The test results will give the investors an opportunity to review the possible solutions and to assess the validity of implementing a thermal modernization.

\section{Building description}

The subject of the study is a single-family house for two families (a four-person and a twoperson family respectively). It is a detached part-basement building with three floors and a difference of levels in the layout. The attic is divided into habitable and non-habitable space. The family of four uses the living room, the sitting room, the kitchen, two toilets, a bathroom, three bedrooms and a guest room. The family of two, on the other hand, utilizes a flat located on the low ground floor consisting of one bedroom with a small kitchen, a bathroom and a toilet. The utility rooms, garage, boiler house and heating fuel shed are located in the basement and are intended to be shared by both families.

The building is located in Siemianice near the city of Stupsk. The location is in Polish climate zone I. The meteorological station located closest to the considered building is in Ustka. The building entrance and the garage entrance are on the south side of the facade. Fig. 1 presents a current photo of the building.

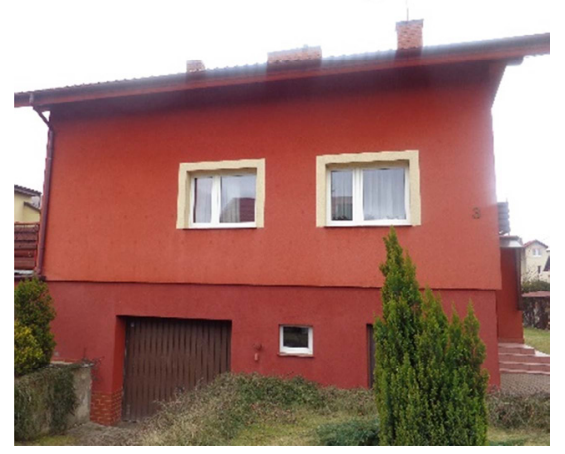

Fig. 1. South building facade [11].

While the building project comes from 1986, the completion of construction and final acceptance took place only in 2002. The sixteen-year period of building construction saw many alterations in relation to the original project. This was caused by the evolving needs of the future inhabitants, updates in the existing legal rules and changes in the building materials market. Current information on the condition of the building, its parameters and changes made to the project was obtained by carrying out an on-site verification, 
performing the necessary measurements and interviewing the inhabitants. On the basis of the inventory and other information received, technical drawings of the building were made. Layouts and cross-section of the building (Fig. 2-3) present the border of energy balancing.
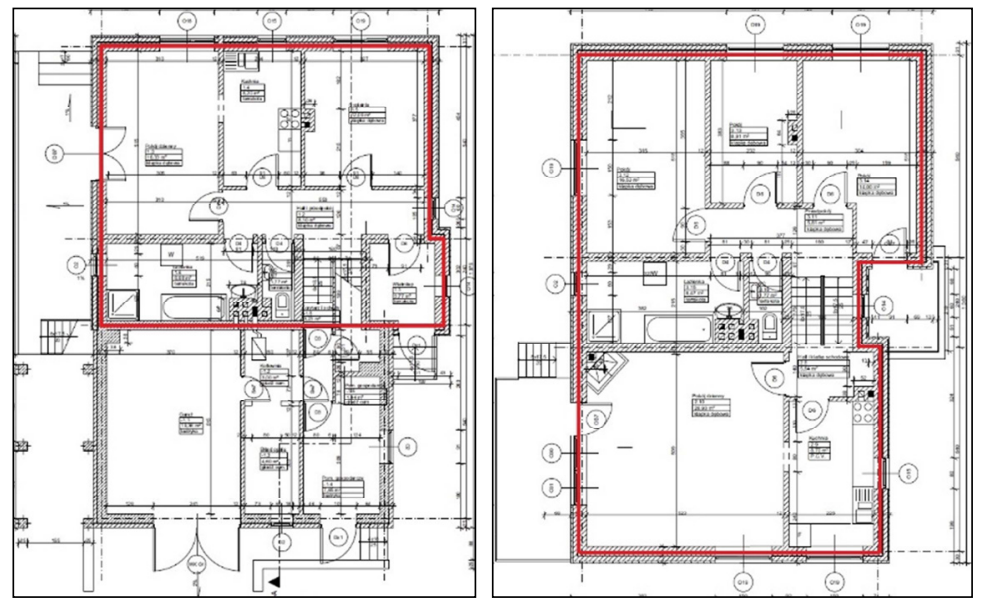

Fig. 2. The ground floor and second floor layout with the delineated energy balancing border [11].

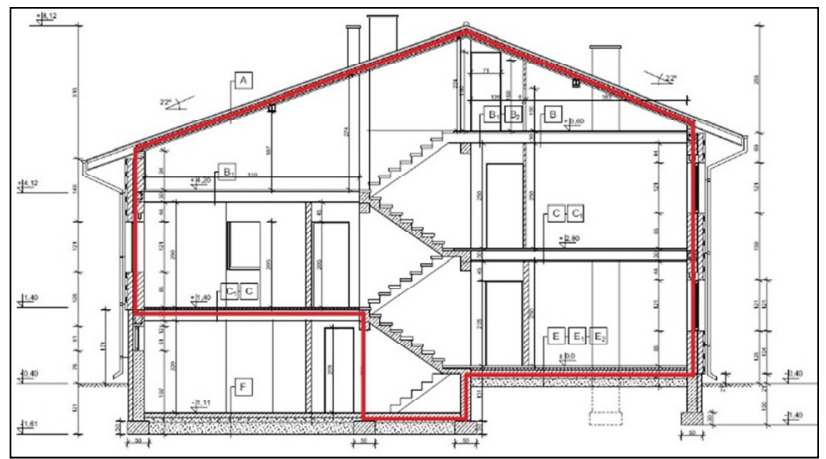

Fig. 3. Cross-section [11].

The building was made with the traditional brick technology. The ceilings in the building are made of prefabricated multi-rib floor slabs type DZ-3 with staircases of monolithic reinforced concrete. The gable roof of steel and wood has a slope angle of $22^{\circ}$. The gross covered area of the building is $126.40 \mathrm{~m}^{2}$ and the total usable heated area is $188.86 \mathrm{~m}^{2}$.

Central heating is powered by a fuel-oil boiler with capacity of $22 \mathrm{~kW}$. Together with the heated storage tank of $130 \mathrm{l}$, the boiler constitutes the heating unit providing heat and the necessary amount of hot water for the building. A fuel tank with a capacity of 1,500 1 with a controller ensures maintenance-free operation.

The current technical condition of the building is good; no excessive humidity is observed. The partitions and other structural elements do not have cracks or excessive deflections. In critical areas, thermal measurements using thermographic cameras were carried out [11]. The examination was performed at a temperature difference of $\Delta \Theta \approx 20^{\circ} \mathrm{C}$, after sunset, with high clouds and no precipitation. In the thermal imaging photos from the outside of the building (Fig. 4-6), a clear heat escape is observed through the uninsulated 
building envelope below the ground floor level. The presented photographs of the outside are for illustrative purposes. Temperatures represented in the thermograms were distorted by the impact of sky radiation. Nevertheless, it is still possible to observe the temperature gradient between the individual surfaces of partitions. Apart from the massive losses of heat occurring in the uninsulated basement walls, point thermal bridges are also clearly visible in the area of mechanical connectors of wall insulation.

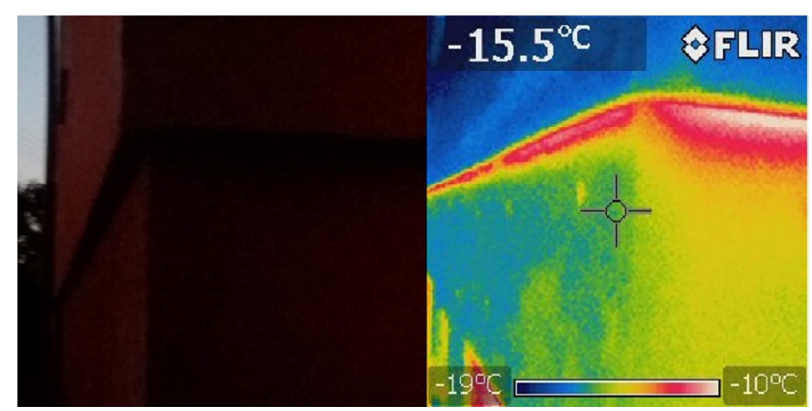

Fig. 4. Thermogram of a basement wall corner [11].

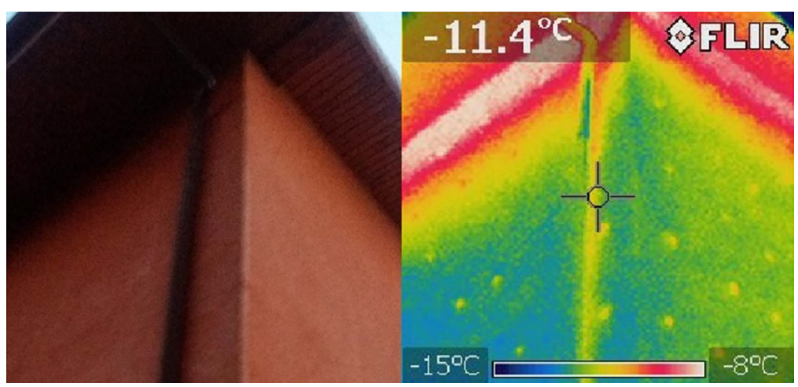

Fig. 5. Thermogram of the outer wall corner and the wall-roof connection [11].

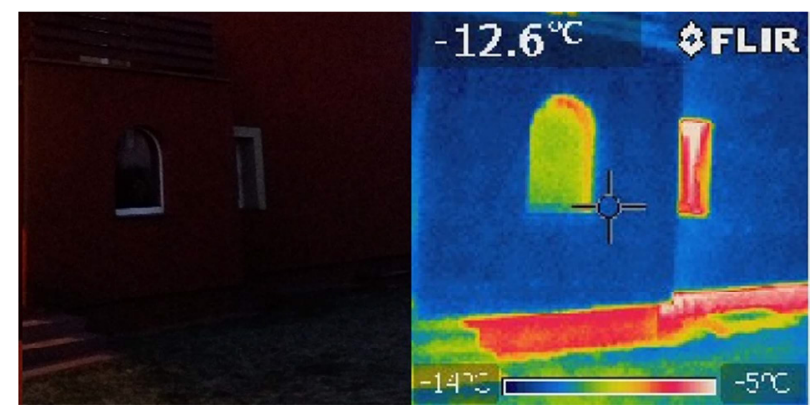

Fig. 6. Thermogram pointing to the lack of insulation of the building base [11].

Thermograms shown in Fig. 7-9 were carried out inside the building. Clearly visible is the linear thermal bridge of the wall-roof connection. The minimum temperature of the wall surface in the corner was $6.7^{\circ} \mathrm{C}$ at an inside temperature of $\sim 20^{\circ} \mathrm{C}$. A similar large heat loss was observed in the basement on the uninsulated ceiling and walls. 


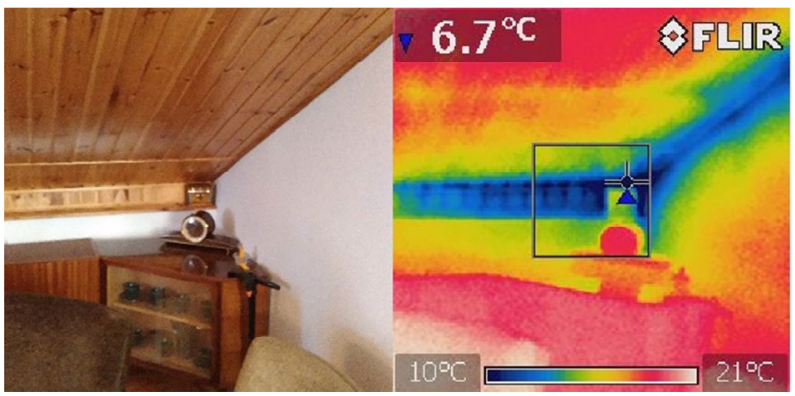

Fig. 7. The thermal bridge resulting from the lack of insulation of the roof-wall connection (from the inside) [11].

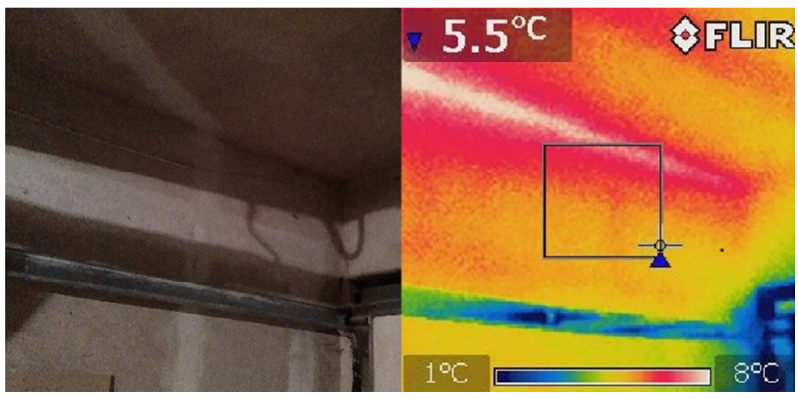

Fig. 8. Thermal bridge resulting from the lack of insulation of the ceiling above the basement (from the inside) [11].

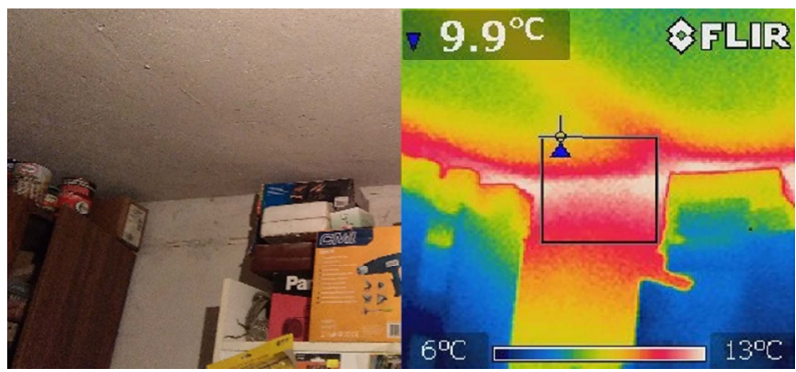

Fig. 9. Thermal bridge resulting from the lack of insulation of the basement walls and ceiling (from the inside) [11].

\section{Calculations for the existing condition}

First, calculations associated with the assessment of thermal insulation of the building partitions were performed. The values of the heat transfer coefficients $U$ of the partitions are given in Table 1. Also, values are given that result from the requirements in terms of technical conditions [12]. The overview shows that the partition walls do not meet the requirements of thermal insulation. What deserves special attention in this case is the uninsulated wall separating the heated space from unheated space, the ceiling over the unheated room and the obsolete window woodwork. 
Table 1. Testing the energy-saving and thermal insulation conditions [11].

\begin{tabular}{|l|c|c|}
\hline \multicolumn{1}{|c|}{ Parameter $\boldsymbol{U}\left[\mathbf{W} /\left(\mathbf{m}^{\mathbf{2}} \mathbf{K}\right)\right]$} & $\begin{array}{c}\text { Value according to [12] } \\
\text { for 2017 }\end{array}$ & Value in this building \\
\hline exterior walls & 0.23 & 0.35 \\
\hline $\begin{array}{l}\text { walls between heated and non-heated cubic } \\
\text { capacity }\end{array}$ & 0.30 & 1.89 \\
\hline roof & 0.18 & 0.28 \\
\hline floor on the ground & 0.30 & 0.20 \\
\hline ceilings over the non-heated areas & 0.25 & 0.57 \\
\hline windows & 1.10 & 2.55 \\
\hline roof windows & 1.30 & 2.70 \\
\hline exterior doors & 1.50 & 2.60 \\
\hline
\end{tabular}

The next step was to calculate the energy balance of the building in the existing condition. The annual primary energy demand factor $E P$ was $394.20 \mathrm{kWh} /\left(\mathrm{m}^{2} \cdot\right.$ year $)$. This value largely exceeds the required level according to [12], i.e. $95 \mathrm{kWh} /\left(\mathrm{m}^{2} \cdot\right.$ year $)$. The calculated energy efficiency of the building shows that its primary energy demand is more than four times higher than expected in the currently existing legislation. Therefore, the building requires a thermal modernization.

\section{Improvement suggestions}

The results of preliminary calculations and thermograms helped in the selection of thermal modernization measures which were aimed at improving the energy efficiency of the building. Optimal improvements were selected leading to the reduction of heat transfer through the doors and windows, walls, ceilings and roof for which the simple payback period takes the minimum value. In the determination of the optimal improvement, the following formula was used:

$$
S P B T=N / \triangle Q[\text { year }]
$$

where:

$N$ - planned expenditures associated with the reduction of losses [PLN], $\Delta Q-$ annual savings of energy costs as a result of modernization [PLN/year].

In the case of woodwork, it was decided to use windows of $U=0.84 \mathrm{~W} / \mathrm{m}^{2} \mathrm{~K}$. The payback period thus obtained was 10.9 years. The additional so-called 'warm' installation of windows in the insulation layer eliminates thermal bridges.

On the other hand, insulating the external walls with polystyrene foam having a thickness of $0.15 \mathrm{~m}$ and $\lambda=0.04 \mathrm{~W} / \mathrm{mK}$ leads to a longer payback period. In this case, $S P B T$ was 18.3 years. The resulting payback periods of the facade works are not satisfactory. The reasons are the high costs of investment, including demolition of the old facade, as well as the relatively small difference between the thermal resistance of the walls before and after implementing the energy upgrade. Nevertheless, it should be kept in mind that in the long run the implementation of new thermal insulation is more effective as it can help to minimize the impact of cold bridges which are not taken into account in the calculation of the SPBT indicator. Among the tested variants, an option was selected which had the shortest payback period and the coefficient $U$ meeting the requirements for the year 2021. 
In the case of thermal insulation of the roof, mineral wool was chosen with a thickness of $0.12 \mathrm{~m}$ and $\lambda=0.039 \mathrm{~W} / \mathrm{mK}$. The SPBT received was 21.4 years. The under-rafter insulation significantly improves the thermal insulation properties of the roof and eliminates the thermal bridge in the wall-roof connection area (Fig. 7).

Another improvement concerns the thermal insulation of the ceiling above the nonheated basement and the walls separating the heated space from the unheated space. The most sensitive places are shown in the thermal camera images (Fig. 8-9). It was decided to install foam polystyrene plates with a thickness of $0.15 \mathrm{~m}$ and $\lambda=0.04 \mathrm{~W} / \mathrm{mK}$ on the wall and the ceiling. The evidence for its cost-effectiveness is the very short payback period which is 1.9 years.

An important method of reducing the cost of heating and domestic hot water is the replacement of the fuel-oil boiler with a biomass boiler. Biomass is considered a renewable source of heat; therefore, it has a low rate of non-renewable primary energy consumption rate for the production and delivery of energy. For biomass, the rate is 0.2 while for fuel oil it is 1.1. This leads to a reduction of primary energy demand $E P$. The costs associated with the replacement of the boiler include the removal of the old system, installation of the new boiler, installing adjustment and system start-up. To reduce costs, it was decided that the hot water tank would not be replaced. The new boiler had to be as easy to use as the old oilfired boiler; therefore, pellet boiler with automatic feed was chosen. Savings resulting from substituting oil with pellets are high enough that, despite significant differences in price between these options, the payback periods are very similar. Because of the large annual savings and the ability to create larger paybacks in the future, the most efficient boiler was selected for which $S P B T$ is 2.3 years.

The simultaneous performance of all the above activities would be costly and would involve an extensive workload. In order to grant the investor the possibility of choice of upgrades appropriate to his needs, it was decided to prepare three relevant options for the purpose of the investment. The proposed options are presented in Table 2.

Table 2. Variants of thermal modernization undertakings.

\begin{tabular}{|l|c|c|c|}
\hline \multicolumn{1}{|c|}{ Thermal modernization undertaking } & $\begin{array}{c}\text { Option 1 } \\
\text { maximum }\end{array}$ & $\begin{array}{c}\text { Option 2 } \\
\text { medium }\end{array}$ & $\begin{array}{c}\text { Option 3 } \\
\text { minimum }\end{array}$ \\
\hline Replacement of windows & $\checkmark$ & $\checkmark$ & \\
\hline Insulation of external walls & $\checkmark$ & & \\
\hline Under-rafter insulation of the roof & $\checkmark$ & & \\
\hline $\begin{array}{l}\text { Insulation of partitions between the non-heated basement } \\
\text { and the heated space }\end{array}$ & $\checkmark$ & $\checkmark$ & $\checkmark$ \\
\hline Replacement of heat source - installation of the pellet boiler & $\checkmark$ & $\checkmark$ & $\checkmark$ \\
\hline
\end{tabular}

The first option consists in performing a full thermal modernization of the building. All the partition walls involved were redesigned to fulfil the conditions contained in the regulation [12]. However, due to high investment cost for the investor, the project feasibility is low. The second option encompasses thermal upgrades with a relatively short payback period. It includes no time-consuming facade works. In this case, it was decided not to intervene in the thermal insulation of the roof. This would help to limit repairs inside the residential part of the building. The third option focuses on modernization work that would not involve the building envelope and its residential part. The repairs would be performed only in the basement. This upgrade would not provide significant energy efficiency improvements of the building; yet it could reduce the heating costs of the building and would pay off very quickly. 


\section{Results and discussions}

The results of the recalculations for the three selected variants compared with the initial condition are summarized in Table 3.

Table 3. Energy characteristics before and after thermal modernization [11].

\begin{tabular}{|l|c|c|c|c|}
\hline \multicolumn{1}{|c|}{ Parameter } & Initial state & $\begin{array}{c}\text { Option 1 } \\
\text { maximum }\end{array}$ & $\begin{array}{c}\text { Option 2 } \\
\text { medium }\end{array}$ & $\begin{array}{c}\text { Option 3 } \\
\text { minimum }\end{array}$ \\
\hline$U\left[\mathrm{~W} / \mathrm{m}^{2} \mathrm{~K}\right]$ for external walls & 0.35 & 0.18 & 0.35 & 0.35 \\
\hline $\begin{array}{l}U\left[\mathrm{~W} / \mathrm{m}^{2} \mathrm{~K}\right] \text { for walls between the heated } \\
\text { and non-heated space }\end{array}$ & 1.89 & 0.23 & 0.23 & 0.23 \\
\hline$U\left[\mathrm{~W} / \mathrm{m}^{2} \mathrm{~K}\right]$ for the roof & 0.28 & 0.15 & 0.28 & 0.28 \\
\hline$U\left[\mathrm{~W} / \mathrm{m}^{2} \mathrm{~K}\right]$ for the ground floor & 0.20 & 0.20 & 0.20 & 0.20 \\
\hline $\begin{array}{l}U\left[\mathrm{~W} / \mathrm{m}^{2} \mathrm{~K}\right] \text { for ceilings over non-heated } \\
\text { rooms }\end{array}$ & 0.57 & 0.18 & 0.18 & 0.18 \\
\hline$U\left[\mathrm{~W} / \mathrm{m}^{2} \mathrm{~K}\right]$ for windows & 2.56 & 0.89 & 0.89 & 2.56 \\
\hline$U\left[\mathrm{~W} / \mathrm{m}^{2} \mathrm{~K}\right]$ for roof windows & 2.70 & 0.89 & 0.89 & 2.70 \\
\hline$E K\left[\mathrm{kWh} /\left(\mathrm{m}^{2}\right.\right.$ year $\left.)\right]$ & 350.09 & 200.47 & 275.26 & 333.38 \\
\hline$E P\left[\mathrm{kWh} /\left(\mathrm{m}^{2}\right.\right.$ year $\left.)\right]$ & 394.20 & 53.49 & 68.41 & 80.08 \\
\hline
\end{tabular}

The results obtained clearly demonstrate that the implementation of the proposed improvements reduces heat transfer coefficients. The data shows that the greatest benefit is achieved in the case when all the proposed improvements are applied (option 1). This also involves the greatest decline in the $E P$ and the $E K$.

All proposed upgrade options are profitable since they entail financial advantages. The decrease in the annual maintenance costs of the building with options 1,2 and 3 are, respectively, $64 \%, 51 \%$ and $41 \%$. The payback periods are, respectively, 5.2, 3.5 and 2.3 years, which is also very satisfactory. Since the options differ significantly in price, the choice largely depends on the financial capacity of the investor.

All the thermal modernization variants involve the use of a biomass boiler. This had the expected significant impact on the primary energy demand factor EP (Fig. 10). Thanks to this solution, even the minimum upgrade variant (option 3) could meet the limit values of the $E P$ factor.

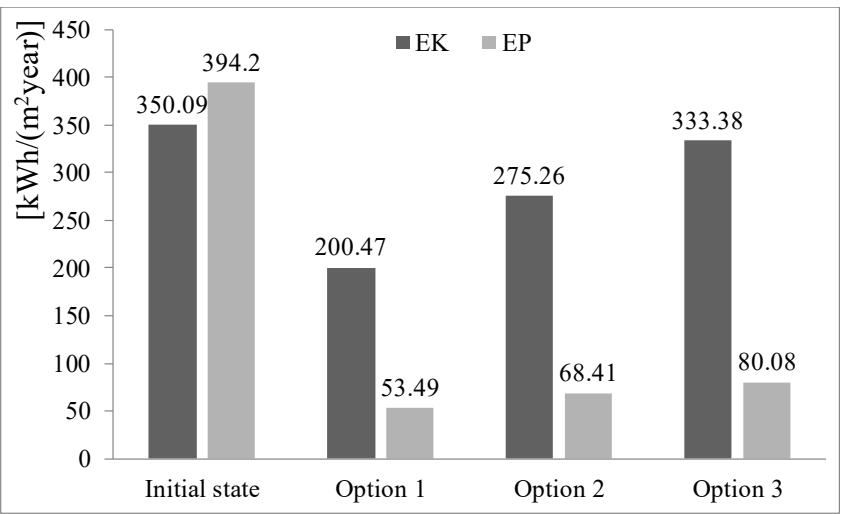

Fig. 10. The $E K$ and $E P$ factors before and after energy upgrade implementation. 
As a result of full modernization (option 1), up to a $43 \%$ reduction of final energy consumption can be expected. After the full thermal modernization, the building meets the requirements set out in the regulation [12]. The middle upgrade option does not involve exterior walls and roof insulation and therefore does not meet these requirements. Despite this, a relatively small investment helps to reduce the final energy consumption by $21 \%$. Similarly, the minimum option does not include insulation of external partitions and as such does not meet the requirements contained in the resolution [12]. The final energy demand in the case of the minimum option was reduced by only 5\%. Still, this variant has an economic justification - it is low-cost, pays back quickly and does not involve renovation works inside the residential part of the building.

\section{Conclusions}

The article presents the results of calculations concerning the energy balance of a building in the existing condition and after the implementation of the three proposed improvement options. Due to the building's outdated technical solutions, insufficient insulation of partitions incompatible with the current requirements and central heating system using expensive non-renewable fuel, all proposed solutions contribute to the improvement of its energy efficiency. The thermal modernization included the replacement of windows, insulation of exterior walls with polystyrene foam, insulation of roof with mineral wool and the under-rafter insulation, insulation of walls and ceilings between the heated and nonheated space and replacement of heat source: installation of a biomass boiler.

Each of the undertakings was characterized by a real payback period and positively influenced the energy efficiency of the building. Three versions of energy upgrade were offered in order for the investor to be able to choose the solution that would best correspond to his financial capacities. The first option involved a full modernization, the second included window replacement, basement insulation and boiler replacement, while the third focused only on basement insulation and boiler replacement.

The proposed change that was crucial was the modernization of the boiler house and the installation of the pellet boiler. Compared to the previously used oil, pellets are a much cheaper fuel. The substitution of the fuel itself saves about $38 \%$ of the annual heating costs. Such large savings make the combination of this improvement with less efficient solutions (e.g., insulation of the exterior walls or roof) result in a very satisfactory investment payback period. Option 1 can serve as an example: the full modernization pays back already after 5.2 years, but the modernization of the exterior walls alone would be paid back after more than 18 years.

Another positive result is the achievement of a high energy efficiency classification of the building after the full modernization. The repairs performed helped all the partitions fulfil the requirements contained in the regulation [12]. In addition, the initial value of the primary energy demand factor $E P=394.2 \mathrm{kWh} /\left(\mathrm{m}^{2}\right.$ year) (before the modernization) decreased to a value of $53.49 \mathrm{kWh} /\left(\mathrm{m}^{2}\right.$ year $)$, i.e. by $86 \%$. The main reason for this is that the modernized boiler uses renewable pellets; therefore, its non-renewable primary energy consumption rate for the production and delivery of energy is very low. Also, a huge change in the demand for final energy was observed. Before the upgrade, it was $350.09 \mathrm{kWh} /\left(\mathrm{m}^{2}\right.$ year $)$, and after it was reduced to $200.47 \mathrm{kWh} /\left(\mathrm{m}^{2}\right.$ year $)$, which is $43 \%$ less.

The decline in energy demand and the substitution of heating fuel together give the building a potential to become much more environmentally friendly and much cheaper to maintain. The cost of maintenance at current fuel prices before the upgrade was 20,725 PLN, falling to 7,474 PLN after the full thermal modernization. Thus, the maintenance costs were reduced by $64 \%$. 
The cost of the full modernization implementation was 69,182 PLN. Far from being a small sum, the investment is still profitable thanks to the above-mentioned savings and the short payback period. Moreover, it should be noted that the full modernization option will help meet the conditions of obtaining a thermal modernization bonus.

The selection one of the three proposed options largely depends on the objectives of the investor. It should be remembered that if he aims at ensuring that the building meets the requirements proposed by the regulation [12] for the year 2017, then the choice of the maximum option containing all the proposed modernization works is necessary.

The problem presented in the article mainly concerns the standard procedure used for the compiling of an energy audit, but the proposed options of thermomodernization are justified according to the user requirements and are feasible.

\section{References}

1. Directive 2002/91/EC of The European Parliament and of The Council of 16 December 2002 on the energy performance of buildings

2. Directive 2010/31/EU of The European Parliament and of The Council of 19 May 2010 on the energy performance of buildings (recast)

3. H. Tommerup, S. Svendsen, Energy savings in Danish residential building Stock. Energ Buildings 38, 618-626 (2006)

4. N. Pardo, C. Thiel, Evaluation of several measures to improve the energy efficiency and $\mathrm{CO}_{2}$ emission in the European single-family houses. Energ Buildings 49, 619-630, (2012)

5. J. Lizana, Á. Barrios-Padura, M. Molina-Huelva, R. Chacartegui, Multi-criteria assessment for the effective decision management in residential energyretrofitting. Energ Buildings 129, 284-307 (2016)

6. E. Antipova, D. Boer, G. Guillén-Gosálbez, L. F. Cabeza, L. Jiménez, Multi-objective optimization coupled with life cycle assessment for retrofitting buildings. Energ Buildings 82, 92-99 (2014)

7. G. P. Panayiotou, S. A. Kalogirou, G. A. Florides, C. N. Maxoulis, A. M. Papadopoulos, M. Neophytou, P. Fokaides, G. Georgiou, A. Symeou, G. Georgakis, The characteristics and the energy behaviour of the residential building stock of Cyprus in view of Directive 2002/91/EC, Energ Buildings 42, 2083-2089 (2010)

8. I. Ballarini, V. Corrado, Application of energy rating methods to the existing building stock: Analysis of some residential buildings in Turin. Energ Buildings 41, 790-800 (2009)

9. M. Hurnik, A. Specjal, Z. Popiolek, W. Kierat, Assessment of single-family house thermal renovation based on comprehensive on-site diagnostics. Energ Buildings 158, 162-171 (2018)

10. C. A. Balaras, K. Droutsa, E. Dascalaki, Simon Kontoyiannidis, Heating energy consumption and resulting environmental impact of European apartment buildings. Energ Buildings 37, 429-442, (2005)

11. M. Szczeciński, Evaluation of selected elements of a residental building energy audit, West Pomeranian University of Technology Szczecin, master thesis, promoter dr inż. A. Stolarska, Szczecin (2017)

12. Dz. U. No. 75 of 2002, item 690 as amended, Regulation of the Minister of Infrastructure of 12 April 2002 on technical conditions of buildings and their location 